\title{
Hybrid K Based Influential Parameter Determination and Design Optimization of 220 kV High Voltage Insulator
}

\author{
Anik Goswami ${ }^{1}$, Paromita Sadhu ${ }^{2}$, Pradip Kumar Sadhu ${ }^{1}$ \\ ${ }^{1}$ Department of Electrical Engineering, Indian Institute of Technology, Indian School of Mines, \\ Dhanbad, Jharkhand-826004, India \\ ${ }^{2}$ Department of Electrical Engineering, Academy of Technology, \\ Adisaptagram, West Bengal-712121, India \\ anik.18dr0026@ee.iitism.ac.in
}

\begin{abstract}
Insulator failure generally occurs due to improper design, and if there exists sharp edges over the insulator surface. There is a need to detect the fragile parameters in the insulator design as they can cause large electrical stress, leading to insulation failure. In this paper, machine learning based approach is used to identify the fragile design parameter and thus determine an optimized design of the insulator, which will eventually decrease the voltage stress over it. A $220 \mathrm{kV}$ insulator is designed and electric field intensity and potential distribution for an assembly of live, ground and insulator is calculated for different geometries. The design parameters of the insulator are considered and varied. The electric field is calculated for the whole assembly of insulator to generate the most optimized design. The optimized design reduces the overall stress by $13.12 \%$.
\end{abstract}

Index Terms-Electric Stress; High Voltage; Insulator; Machine Learning Algorithms.

\section{INTRODUCTION}

Advancement in technology has led to the modernization and urbanization of all the nations across the world. This has increased the need of reliable power supply. One of the major hindrance of which is insulation failure. Insulation failure occurs mainly due to the increase in the electrical stress over the insulator surface. The study of stress on the insulator surface at the solid and air boundary is of prime importance for determining the reliability of the insulator.

In extra high voltage systems, a detailed knowledge of the electric field distribution is necessary for increasing the reliability and life span of the designed insulator. Threedimensional electrical field calculated from the surface charge simulation method [1], [2] is used in designing optimal insulator. However, in [3] electromagnetic field is obtained using direct boundary element method. The finite element method in [4], [5] shows the electric field and the ion current density generated at the ground level due to the conductors. The insulator contour design is of prime importance as well, in order to have minimal tangential force on the insulator [6]. Genetic algorithm is used for contour optimization of a suspension type insulator with the aim to

Manuscript received 5 December, 2018; accepted 8 April, 2019 minimize the electrical stress [7], [8]. For operation of composite insulators the electric stress on the surface of the insulator is a major factor [9], [10]. In [11], the electrical stress is calculated for $1000 \mathrm{kV}$ insulator using boundary element method and 3-D software package. The shape optimization of the cap and the pin of the insulator is done using Particle Swarm Optimization (PSO). Studies show that the electrical stress depends on the design dimensions of the cap and the pin. Hence, proper design is required to achieve minimum electrical stress on the insulator body [12], [13].

Commercially available insulators fail majorly due to the excessive voltage stress on certain points on the insulator surface. Insulators face high voltage stress generally at bends, sharp edges, and air-dielectric boundaries. There is a need to determine these weak points on the insulator surface, so that adequate precautions can be taken. In this paper, a $220 \mathrm{kV}$ insulator is simulated and the voltage stress over the body of the insulator is studied. The analysis is done by varying the different design parameters of the insulator. Since there is more than one parameter varying, hybrid K algorithm is used to determine the most fragile design parameter [14]. This helps in development of the optimal insulator design. The voltage stress of the designed insulator is reduced significantly, thus reducing the stress at the fragile points. Facilities can monitor the stress at these sensitive points to determine the health of the insulator and take adequate precautions. Manufacturers may use the optimal model to develop insulators with reduced voltage stress, thus improving reliability and improved life expectancy.

\section{ELECTRIC FIELD ANALYSIS}

Boundary Element Method (BEM) is used for computation of Electric Field. The mathematical foundation of BEM depends on solution of partial differential equations in the region by means of boundary values [15], [16]. It is known as classical boundary value problem. In potential theory the formula is presented as shown in (1)

$$
\begin{aligned}
& u(x)=\mathrm{J} \delta_{n(y)} \gamma(x, y)[u(y)] \tau d_{0}(y)- \\
& -\int_{\tau} \gamma(x, y)\left[\delta_{n(y)} u(y)\right] \tau d_{0}(y),
\end{aligned}
$$


for $x \in R^{n} \backslash \tau$, where $\gamma(x)$ is any fundamental solution of differential equation, $u(x)$ is a harmonic function, $\delta_{n}$ is normal derivative taken with respect to the exterior normal on $\tau$, and $d_{0}$ is a surface measure on $\tau$.

For any point $i$ on the electrode surface the potential $\varphi$ is calculated according to (2)

$$
\varphi(i)=\frac{1}{4 \pi \varepsilon_{0}\left[\sum_{a=1}^{a^{\prime}} \int_{S_{a}} \frac{\sigma(P)}{r P_{i}} d S a+\sum_{b=1}^{b^{\prime}} \int_{S_{b}} \frac{\sigma(Q)}{r Q_{i}} d S b\right]},
$$

where $s$ is a surface of the insulator; $P$ is charge density for the region $s_{a}, Q$ is charge density for the region $s_{b}, r$ is radius, $\sigma_{s}$ is a surface charge density, and $\varepsilon_{0}$ is the vacuum permittivity.

The potential at any point $k$ due to a surface charge density at any point $\mathrm{P}$ located over any surface element $s_{s e}$ is given by

$$
\varphi_{k}=\frac{1}{4 \pi \varepsilon_{0}} \sum_{s e=1}^{S_{E}} \int_{S_{s e}} \frac{\sigma_{s e}}{r_{P k}} d S e,
$$

where $s_{E}$ is total number of surface elements and

$$
\begin{aligned}
& \sigma(k)=\frac{2 \sigma_{s}(k)}{\varepsilon_{1}+\varepsilon_{2}}+2 \varepsilon_{0} \frac{\varepsilon_{1}-\varepsilon_{2}}{\varepsilon_{1}+\varepsilon_{2}} \times \\
& \times \sum_{s e=1}^{S_{E}} \int_{S_{s e}} \frac{\sigma_{s e} \cos \left(r_{P k}, n_{k}\right)}{r_{P k}} d s e, \quad[\mathrm{P} \neq \mathrm{k}],
\end{aligned}
$$

where $\varepsilon_{1}$ is the relative permittivity from side orientation 1 , $\varepsilon_{2}$ is the relative permittivity from side orientation 2 .

To obtain the numerical solution of (4), basis function of different order is required for approximating the surface charge $\sigma$. The basis function is given by

$$
\phi=\sum_{i=1}^{n} N_{i} \phi_{i} .
$$

The basis function will calculate the value of the function at any given point on that boundary. The basis function is conveniently expressed in L-coordinate system [17]. For triangular boundary the linear approximation is given by

$$
\phi=\left[L_{1} L_{2} L_{3}\right]\left\lfloor\begin{array}{l}
\phi_{1} \\
\phi_{1} \\
\phi 3
\end{array}\right\rfloor,
$$

where

$$
L_{1}+L_{2}+L_{3}=\frac{A_{1}}{A}+\frac{A_{2}}{A}+\frac{A_{3}}{A}=1,
$$

and $A$ is a total area of surface, and $A_{i}$ is the area between various triangular points.

Boundary elements are approximated by first order polynomial. Hence, for triangular boundary element the number of nodes is 3 . The surface charges are located at the vertices of the triangular boundary elements.

The contribution of the observed element to the potential at any arbitrary point $\mathrm{G}$ is given by

$$
\begin{gathered}
\varphi_{\text {elec }} G=\frac{1}{4 \pi \varepsilon_{0}} \times \\
\times \int_{0}^{1} \int_{0}^{1-\varepsilon} \varepsilon \sigma_{1}+n \sigma_{2}+\left(\frac{(1-\varepsilon-n) \sigma_{3}}{r_{I G}(\varepsilon, n)}\left|J\left(L_{1}, L_{2}\right)\right| d L_{1} L_{2}\right),
\end{gathered}
$$

where $J\left(L_{1}, L_{2}\right)$ is the Jacobian of the transformation.

If expressed as set of linear equations, then (8) reduces to

$$
[A][\sigma]=[V]
$$

where $[A]$ is a coefficient matrix, $[V]$ is a column vector describing the potential at the node on the electrode surfaces, and $[\sigma]$ is a matrix of the equivalent charge at the node.

\section{HYBRID K BASED CLUSTERING}

K-means cluster can create very tight cluster for large number of variables [18]. Whereas linear regression gives very fast results and is used to determine the dependence of one variable on other [19]. The hybrid K clustering algorithm model takes the advantage of both K-means clustering and linear regression. The present problem is a multi-variable optimization problem. The variables do not have a linear relationship among themselves and they are not homogeneous. So, there is a requirement of forming groups among the variables and, then, predicting the output. Thus, traditional regression or $\mathrm{K}$ based clustering will not produce good results. Hybrid $\mathrm{K}$ based clustering with linear regression model is suitable, in this case, as regression data can become the centroid of the clustered data, which gives better correlation between the variables.

In K-means optimization problem, the loss function is required to be minimized. The loss function is of the form

$$
L_{k}=\sum_{j=1}^{n} \sum_{r \in R}\left(x_{j, r}-\alpha_{k(j), r}\right)^{2}
$$

where $\alpha_{k(j)}$ is the centroid of the cluster. The Euclidean distance of a point $x_{j}$ of a finite set $R$ from the centroid is to be minimized.

In linear regression, the loss function of each point from its regression hyper-plane is given in (11)

$$
L_{r}=\sum_{j=1}^{n}\left(y_{j}-\left(a_{k(j)}^{T} x_{j}+b_{k(j)}\right)\right)^{2},
$$

where $y=\sum a_{k} x_{j}+b_{k}$ is the linear regression model.

In hybrid $\mathrm{K}$ - means optimization, the clustering follows the integrated loss function

$$
L_{k, r}=p L_{r}+(1-p) L_{k} .
$$


In each iteration, the loss function is minimized. When the loss function reaches a global or local optimum, the algorithm stops and, hence, the optimum centroid point is found.

\section{INSULATOR DESIGN}

The model under consideration is a $220 \mathrm{kV}$ long rod silicon composite insulator. The description of the model is as follows:

- Number of sheds $=36($ big $)+35($ small $)=71$;

- Minimum distance between the sheds $=51 \mathrm{~mm}$;

- Creepage distance $=7801 \mathrm{~mm}$;

- Dry arching distance $=1928 \mathrm{~mm}$;

- Angle of the sheds $=6^{0}$.

Figure 1 shows the design specification of the actual insulator.

The parameters under consideration are:

- Flange angle $(\theta)$;

- Flange radius $\left(r_{0}\right)$;

- Core radius $\left(r_{i}\right)$;

- Insulator outer edge radius $\left(\mathrm{r}_{\mathrm{os}}\right)$;

- Electrode radius $\left(r_{p}\right)$.

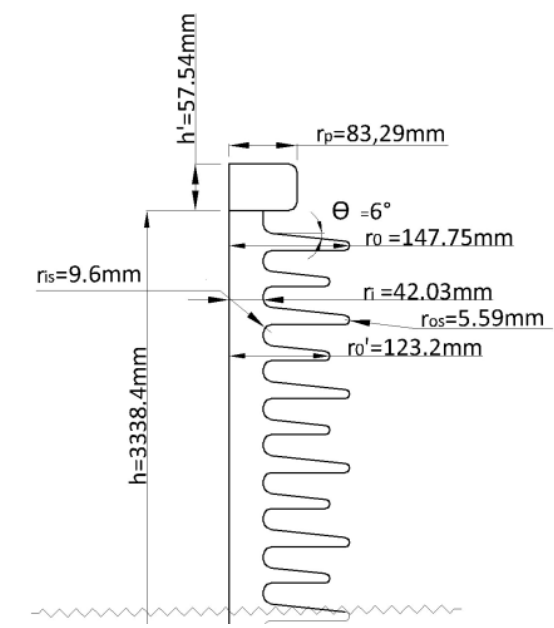

Fig. 1. Insulator design specifications.

The parameter values are varied within the range of practical application and the influence of these variations on the electric field distribution for step voltage is studied.

\section{EFFECT OF CHANGE IN FLANGE ANGLE}

In this case, the $r_{0}=147.75 \mathrm{~mm}, \quad r_{\mathrm{i}}=42.03 \mathrm{~mm}$, $r_{o s}=5.59 \mathrm{~mm}$, insulator height $(h)=3338.4 \mathrm{~mm}$, are all kept constant. The slope angle $(\theta)$ is originally $6^{\circ}$. Now, it is decreased and increased by $2^{\circ}$, in steps of $1^{\circ}$. The results are presented in Table I. From Table I, it can be observed that for $8^{\circ}$ the stress is minimum. So, now the original design is modified and the slope angle is taken as $8^{\circ}$.

TABLE I. CHANGE IN STRESS FOR CHANGE IN SLOPE ANGLE

\begin{tabular}{|c|c|c|}
\hline $\begin{array}{c}\text { Flange angle }(\boldsymbol{\theta}) \text { in } \\
(\boldsymbol{})\end{array}$ & $\begin{array}{c}\text { Electrical Stress } \\
(\mathbf{V} / \mathbf{m})\end{array}$ & $\begin{array}{c}\text { Percentage Change } \\
(\boldsymbol{\%})\end{array}$ \\
\hline 6 (Original) & 0.001638 & 0 \\
\hline 5 & 0.001644 & 0.366 \\
\hline 4 & 0.001680 & 2.56 \\
\hline 7 & 0.001634 & -0.244 \\
\hline 8 & 0.001602 & -2.19 \\
\hline
\end{tabular}

\section{EFFECT OF CHANGE IN FLANGE RADIUS}

In this case, the $\theta=8^{\circ}, r_{i}=42.03 \mathrm{~mm}$, and $r_{o s}=5.59 \mathrm{~mm}$ are all kept constant. The flange radius $r_{0}$ and $r_{0}^{\prime}$ are decreased and increased by $10 \mathrm{~mm}$.

The variation of the electrical stress with change flange radius is presented in Table II.

TABLE II. CHANGE IN STRESS FOR CHANGE IN FLANGE RADIUS.

\begin{tabular}{|c|c|c|c|}
\hline $\begin{array}{c}\text { Bigger Flange } \\
\text { Radius }\left(\boldsymbol{r}_{\mathbf{0}}\right) \\
(\mathbf{m m})\end{array}$ & $\begin{array}{c}\text { Smaller Flange } \\
\text { Radius }\left(\boldsymbol{r}_{\mathbf{0}}{ }^{\prime}\right) \\
(\mathbf{m m})\end{array}$ & $\begin{array}{c}\text { Electrical } \\
\text { Stress } \\
(\mathbf{V} / \mathbf{m})\end{array}$ & $\begin{array}{c}\text { Percentage } \\
\text { Change } \\
(\boldsymbol{\%})\end{array}$ \\
\hline 147.75 & 123.2 & 0.001638 & 0 \\
\hline 127.75 & 103.2 & 0.001604 & -2.075 \\
\hline 137.75 & 113.2 & 0.001590 & -2.93 \\
\hline 157.75 & 133.2 & 0.001632 & -0.366 \\
\hline
\end{tabular}

From Table II, it is seen that for $r_{0}=137.75 \mathrm{~mm}$ and $r_{0}^{\prime}=113.2 \mathrm{~mm}$ the stress is minimum. So, now the original design is modified and the slope angle is taken as $8^{\circ}$, and flange radius is taken as $r_{0}=137.75 \mathrm{~mm}$ and $r_{0}=113.2 \mathrm{~mm}$.

\section{EFFECT OF CHANGE IN MEAN RADIUS}

In this case, the $\theta=8^{\circ}, r_{O S}=5.59 \mathrm{~mm}, r_{0}=137.75 \mathrm{~mm}$, and $r_{0}{ }^{\prime}=113.2 \mathrm{~mm}$, these are all kept constant. The mean radius $r_{i}$ is decreased and increased by $2 \mathrm{~mm}$. The variation of the electrical stress with the mean radius is presented in Table III.

TABLE III. CHANGE IN STRESS FOR CHANGE IN MEAN RADIUS.
\begin{tabular}{|c|c|c|}
\hline $\begin{array}{c}\text { Mean Radius }\left(\boldsymbol{r}_{\boldsymbol{i}}\right) \\
(\mathbf{m m})\end{array}$ & $\begin{array}{c}\text { Electrical Stress } \\
(\mathbf{V} / \mathbf{m})\end{array}$ & $\begin{array}{c}\text { Percentage } \\
\text { Change } \\
(\boldsymbol{\%})\end{array}$ \\
\hline 42 & 0.001638 & 0 \\
\hline 38 & 0.001648 & 0.61 \\
\hline 40 & 0.001630 & 0.488 \\
\hline 44 & 0.001584 & -3.29 \\
\hline 46 & 0.001566 & -4.39 \\
\hline 48 & 0.001572 & -4.02 \\
\hline
\end{tabular}

From Table III, it is seen that for $r_{i}=44 \mathrm{~mm}$ the stress is minimum. So, now the original design is modified and the slope angle is taken as $8^{\circ}$, and flange radius is taken as $r_{0}=137.75 \mathrm{~mm}$ and $r_{0}=113.2 \mathrm{~mm}$ and $r_{i}=44 \mathrm{~mm}$.

\section{EFFECT OF CHANGE IN OUTER RADIUS}

In this case, the $\theta=8^{\circ}, r_{0}=137.75 \mathrm{~mm}, r_{0}^{\prime}=113.2 \mathrm{~mm}$, and $r_{i}=44 \mathrm{~mm}$, these are all kept constant. The outer radius $r_{o s}$ is decreased and increased by $1 \mathrm{~mm}$. The variation of the electrical stress with the outer radius is presented in Table IV.

TABLE IV. CHANGE IN STRESS FOR CHANGE IN OUTER RADIUS.

\begin{tabular}{|c|c|c|}
\hline $\begin{array}{c}\text { Outer Radius }\left(\boldsymbol{r}_{\boldsymbol{o s}}\right) \\
(\mathbf{m m})\end{array}$ & $\begin{array}{c}\text { Electrical Stress } \\
(\mathbf{V} / \mathbf{m})\end{array}$ & $\begin{array}{c}\text { Percentage Change } \\
(\mathbf{\%})\end{array}$ \\
\hline 5.59 & 0.001638 & 0 \\
\hline 4.59 & 0.00164 & 0.12 \\
\hline 3.59 & 0.001647 & 0.55 \\
\hline 6.59 & 0.001475 & -9.95 \\
\hline 7.59 & 0.001705 & 4.09 \\
\hline
\end{tabular}

From Table IV, it is seen that for $r_{o s}=6.59 \mathrm{~mm}$ the stress is minimum. With a decrement of $1 \mathrm{~mm}$ from the original outer radius the electric stress on the insulator is decreased by $9.95 \%$. So, now the original design is modified and the slope angle is taken as $8^{\circ}$, and flange radius is taken as 
$r_{0}=137.75 \mathrm{~mm}$, and $r_{0}^{\prime}=113.2 \mathrm{~mm}$, and $r_{i}=44 \mathrm{~mm}$, and $r_{o s}=6.59 \mathrm{~mm}$. The next change is to vary the electrode radius.

\section{EFFECT OF CHANGE IN ELECTRODE RADIUS}

In this case, the $\theta=8^{\circ}, r_{o s}=6.59 \mathrm{~mm}, r_{0}=137.75 \mathrm{~mm}$, $r_{0}^{\prime}=113.2 \mathrm{~mm}$, and $r_{i}=44 \mathrm{~mm}$, these are all kept constant. The electrode radius $r_{p}$ is decreased and increased by $5 \mathrm{~mm}$. The variation of the electrical stress with change electrode radius is presented in Table $\mathrm{V}$.

TABLE V. CHANGE IN STRESS FOR CHANGE IN ELECTRODE RADIUS.

\begin{tabular}{|c|c|c|}
\hline $\begin{array}{c}\text { Electrode Radius }\left(\boldsymbol{r}_{\boldsymbol{p}}\right) \\
(\mathbf{m m})\end{array}$ & $\begin{array}{c}\text { Electrical Stress } \\
(\mathbf{V} / \mathbf{m})\end{array}$ & $\begin{array}{c}\text { Percentage } \\
\text { Change } \\
(\mathbf{\%})\end{array}$ \\
\hline 83.29 & 0.001638 & 0 \\
\hline 73.29 & 0.001523 & -7.02 \\
\hline 78.29 & 0.001500 & -8.42 \\
\hline 88.29 & 0.001450 & -11.47 \\
\hline 92.29 & 0.001423 & -13.12 \\
\hline \multicolumn{3}{|c}{} \\
\hline \multicolumn{2}{|c}{} \\
\hline
\end{tabular}

From Table V, it is seen that for $r_{p}=92.29 \mathrm{~mm}$ the stress is minimum. So, now the original design is modified and the slope angle is taken as $8^{\circ}$, flange radius is taken as $r_{0}=137.75 \mathrm{~mm}$, and $r_{0}=113.2 \mathrm{~mm}$, and $r_{i}=44 \mathrm{~mm}$, and $r_{o s}=6.59 \mathrm{~mm}$, and $r_{p}=92.29 \mathrm{~mm}$.

\section{Prediction of Influential Design PARAMETER}

An analysis is carried to find out the dependence of the output on the input parameters and, hence, determine the most critical input parameter. Table VI shows the analysis of variance.

TABLE VI. ANALYSIS OF VARIANCE.

\begin{tabular}{|c|c|c|c|c|c|}
\hline Source & DF & $\begin{array}{c}\text { Sum of } \\
\text { Squares }\end{array}$ & $\begin{array}{c}\text { Mean } \\
\text { Square }\end{array}$ & $\begin{array}{c}\text { F } \\
\text { Value }\end{array}$ & Pr > F \\
\hline Model & 1 & $\begin{array}{c}4.30268 \\
\times 10-8\end{array}$ & $\begin{array}{c}4.302686 \\
\times 10-8\end{array}$ & 10.72 & 0.0040 \\
\hline Error & 19 & $\begin{array}{c}7.62382 \\
\times 10-8\end{array}$ & $\begin{array}{c}4.012254 \\
\times 10-9\end{array}$ & -- & -- \\
\hline $\begin{array}{c}\text { Corrected } \\
\text { Total }\end{array}$ & 20 & $\begin{array}{c}1.92651 \\
\times 10-7\end{array}$ & $-2.93 \%$ & -- & -- \\
\hline
\end{tabular}

The gradient of the predictor variable is 0 , as seen from the $\mathrm{F}$ value test. The p-value being small (less than 0.05 ), there is adequate indication to reject the null hypothesis at the 0.5 significance level. It is seen that the hybrid linear regression model suits the data better than the baseline model [20].

TABLE VII. SUMMARY OF THE MEASURES.

\begin{tabular}{|c|c|c|c|c|}
\hline Root MSE & R-Square & $\begin{array}{c}\text { Dependent } \\
\text { Mean }\end{array}$ & $\begin{array}{c}\text { Adj R- } \\
\text { Square }\end{array}$ & $\begin{array}{c}\text { Coeff } \\
\text { Var }\end{array}$ \\
\hline 0.0000633 & 0.3608 & 0.00159 & 0.3271 & 3.977 \\
\hline
\end{tabular}

From Table VII, it is observed that the proportion of variability witnessed in the data is 0.3608 . So, $36 \%$ of the total deviation in the output values can be explained by the regression line.

\section{MODEL BUILDING AND INTERPRETATION}

The objective is to determine the Linear Regression task for model selection. Each of design parameters are assigned with a variable:

$-\mathrm{X}_{1}=$ Flange angle $(\theta)$;

$-\mathrm{X}_{2}=$ Flange radius $\left(r_{0}\right)$;

$-\mathrm{X}_{3}=$ Core radius $\left(r_{i}\right)$;

$-\mathrm{X}_{4}=$ Insulator outer edge radius $\left(r_{o s}\right)$;

$-\mathrm{X}_{5}=$ Electrode radius $\left(r_{p}\right)$.

Table VIII shows the result of linear regression. Mallow's $C_{p}$ and Hocking's Criteria are used to indicate model bias [21]. The models having $C_{p}$ values near to $\mathrm{p}$ (the number of variables in the design and the intercept) are considered.

\begin{tabular}{|c|c|c|c|c|}
\hline $\begin{array}{l}\text { Model } \\
\text { Index }\end{array}$ & $\begin{array}{l}\text { Number } \\
\text { in Model }\end{array}$ & $C_{p}$ & $\begin{array}{c}\text { R- } \\
\text { Square }\end{array}$ & Variables in Model \\
\hline 1 & 2 & 5.0321 & 0.4838 & $\mathrm{X} 3 \mathrm{X} 4$ \\
\hline 2 & 3 & 5.0936 & 0.5338 & $\mathrm{X} 2 \mathrm{X} 3 \mathrm{X} 4$ \\
\hline 3 & 3 & 5.1076 & 0.5334 & X1 X3 X4 \\
\hline 4 & 3 & 5.1742 & 0.5317 & X3 X4 X5 \\
\hline 5 & 4 & 5.2278 & 0.5818 & $\mathrm{X} 2 \mathrm{X} 3 \mathrm{X} 4 \mathrm{X} 5$ \\
\hline 6 & 4 & 5.2430 & 0.5814 & X1 X3 X4 X5 \\
\hline 7 & 2 & 5.8420 & 0.4629 & $\mathrm{X} 2 \mathrm{X} 4$ \\
\hline 8 & 4 & 5.8698 & 0.5653 & $\mathrm{X} 1 \mathrm{X} 2 \mathrm{X} 3 \mathrm{X} 4$ \\
\hline 9 & 3 & 5.8717 & 0.5137 & $\mathrm{X} 1 \mathrm{X} 2 \mathrm{X} 4$ \\
\hline 10 & 5 & 6.0000 & 0.6135 & X1 X2 X3 X4 X5 \\
\hline 11 & 3 & 6.0234 & 0.5098 & $\mathrm{X} 2 \mathrm{X} 4 \mathrm{X} 5$ \\
\hline 12 & 4 & 6.1405 & 0.5609 & $\mathrm{X} 1 \mathrm{X} 2 \mathrm{X} 4 \mathrm{X} 5$ \\
\hline 13 & 2 & 6.1579 & 0.4548 & $\mathrm{X} 1 \mathrm{X} 4$ \\
\hline 14 & 3 & 6.3446 & 0.5015 & $\mathrm{X} 1 \mathrm{X} 4 \mathrm{X} 5$ \\
\hline 15 & 1 & 7.8072 & 0.3608 & $\mathrm{X} 4$ \\
\hline 16 & 2 & 8.0182 & 0.4069 & $\mathrm{X} 4 \mathrm{X} 5$ \\
\hline 17 & 2 & 12.178 & 0.2997 & $\mathrm{X} 2 \mathrm{X} 3$ \\
\hline 18 & 2 & 12.255 & 0.2977 & $\mathrm{X} 1 \mathrm{X} 3$ \\
\hline 19 & 3 & 12.403 & 0.3454 & $\mathrm{X} 2 \mathrm{X} 3 \mathrm{X} 5$ \\
\hline 20 & 3 & 12.482 & 0.3434 & X1 X3 X5 \\
\hline 21 & 1 & 12.511 & 0.2396 & $\mathrm{X} 3$ \\
\hline 22 & 2 & 12.746 & 0.2850 & $\mathrm{X} 3 \mathrm{X} 5$ \\
\hline 23 & 3 & 12.758 & 0.3362 & $\mathrm{X} 1 \mathrm{X} 2 \mathrm{X} 3$ \\
\hline 24 & 4 & 12.978 & 0.3821 & $\mathrm{X} 1 \mathrm{X} 2 \mathrm{X} 3 \mathrm{X} 5$ \\
\hline 25 & 2 & 15.176 & 0.2224 & $\mathrm{X} 1 \mathrm{X} 2$ \\
\hline 26 & 3 & 15.466 & 0.2665 & $\mathrm{X} 1 \mathrm{X} 2 \mathrm{X} 5$ \\
\hline 27 & 1 & 15.904 & 0.1521 & $\mathrm{X} 2$ \\
\hline 28 & 2 & 16.213 & 0.1957 & $\mathrm{X} 2 \mathrm{X} 5$ \\
\hline 29 & 1 & 16.564 & 0.1351 & $\mathrm{X} 1$ \\
\hline 30 & 2 & 16.882 & 0.1785 & $\mathrm{X} 1 \mathrm{X} 5$ \\
\hline 31 & 1 & 20.162 & 0.0424 & $\mathrm{X5}$ \\
\hline
\end{tabular}

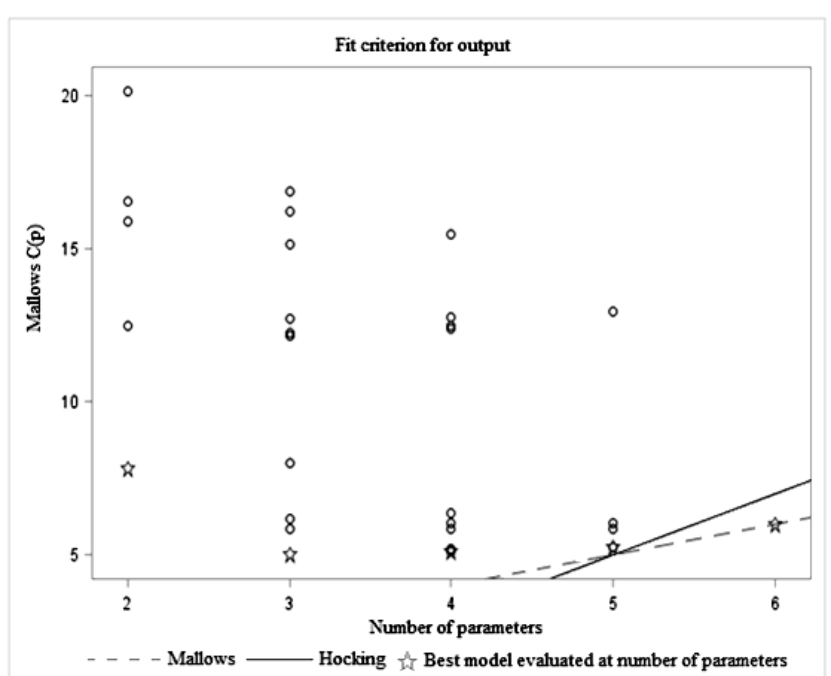

Fig. 2. Mallow's C(p) plot.

The model with the fewest variable, where $C_{p}$ value is taken close to $\mathrm{p},(13)$ gives the estimate of $C_{p}$ 


$$
C_{p}=m+\frac{\left(M S E_{m}-M S E_{t o t}\right)(n-m)}{M S E_{t o t}},
$$

where $M S E_{m}$ is the mean squared error for the model with $\mathrm{m}$ parameters, $M S E_{t o t}$ is the mean squared error of the complete model used to determine the actual residual value, $n$ is the number of observation, and $m$ is the number of parameters including the intercept parameter.

From Fig. 2, it is observed that the best model is evaluated when the number of parameters is 4 .

\section{INFLUENTIAL PARAMETER ANALYSIS}

Influential parameter is determined using Cook's D analysis [22]. As it can be seen in Fig. 3, the observation 14 is maximum and the value is 1.85 , which is much more than three times the mean value, which is 0.25 . So, according to the thumb rule, it can be concluded that observation 14 in Table VIII is the possible outliner.

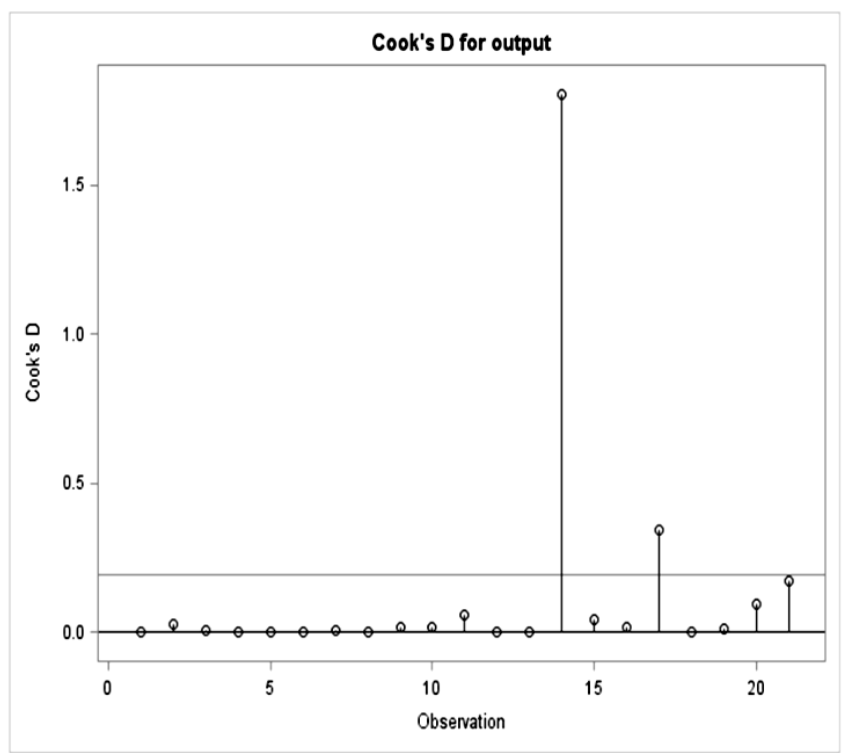

Fig. 3. Cook's D plot for the model.

Figure 4 gives the DFFITS plot [23]. From Fig. 4, it is observed that $\mathrm{X}_{4}$ has the highest influence on the output of the model. $\mathrm{X}_{4}$ is having a value of 4 , which is much higher than the values of the other inputs.

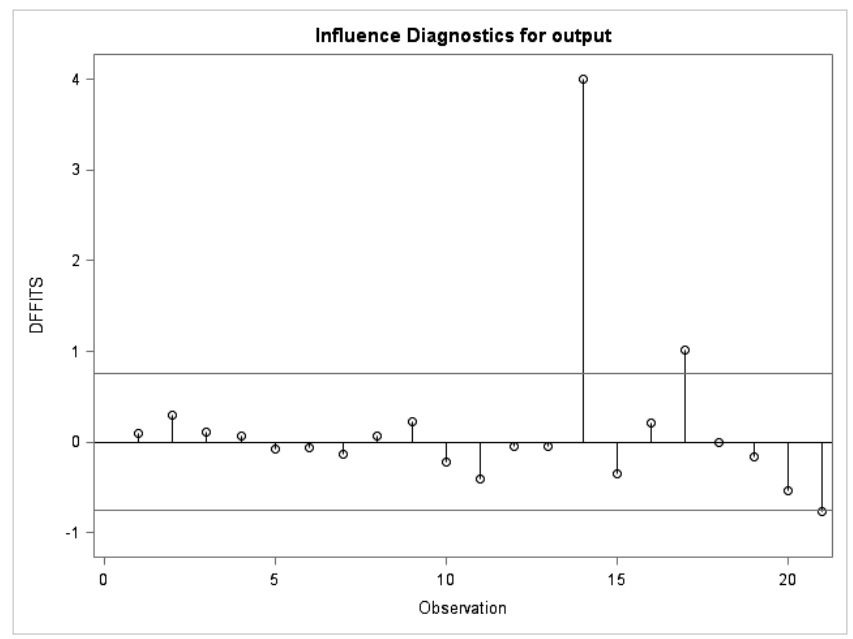

Fig. 4. DFFITS plot for the model.
From DFBETAS plot in Fig. 5, it is observed that $\mathrm{X}_{4}$ has the highest influence on the output. From the three influence models, it can be concluded that the parameter $\mathrm{X}_{4}$ (insulator outer edge radius) is the most important parameter in the design of the insulator.

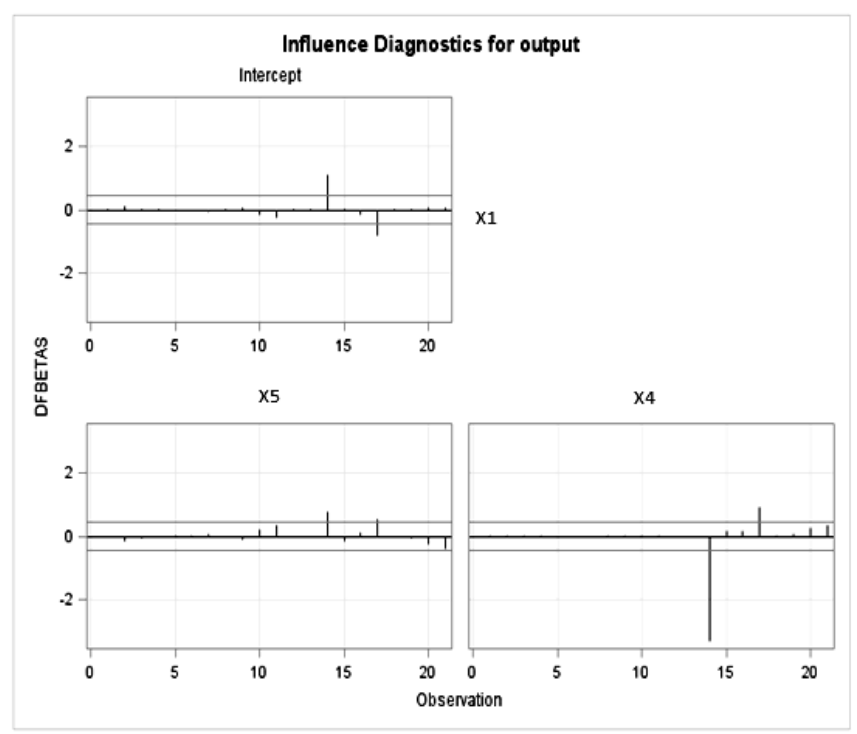

Fig. 5. DFBETAS plot for the model.

\section{RESULTS AND DISCUSSIONS}

From Table I,II,III,IV, and V, it can be observed that the design configuration that leads to the minimum electrical stress on the insulator is when slope angle is taken as $8^{\circ}$ and flange radius is taken as $r_{0}=137.75 \mathrm{~mm}$, and $r_{0}^{\prime}=113.2 \mathrm{~mm}$, and $r_{i}=44 \mathrm{~mm}$, and $r_{o s}=6.59 \mathrm{~mm}$, and $r_{p}=92.29 \mathrm{~mm}$. A data set of 15000 input parameters is taken as the training set for the simulation using hybrid $\mathrm{K}$ based clustering approach. Another data set, consisting of 3000 data, is taken as testing input. Each epoch consisted of 36 samples out of the 15000 input parameters, the iteration was continued till the whole set is traversed. Form Table VI, it is seen that the mean square error is $4.012254 \times 10^{-9}$ and having a corrected total of $1.92651 \times 10^{-7}$. The corrected total signifies that the difference between the training set and the testing set is very low and the output is having a high accuracy. This suggests that the trained network performed an excellent job in predicting the electrical stress at each point. From Table VII, it is seen that the regression line explains $36 \%$ of the total variation in the response values From Mallow's $C_{p}$ test and Hocking's criteria, it is predicted that the output presents the highest accuracy when the number variable of input parameters is taken as 4. From Cook's plot, it is observed that flange angle $(\theta)$, insulator outer edge radius $\left(r_{o s}\right)$, and electrode radius $\left(r_{p}\right)$ are the most influential parameters, which have a huge impact on the electric stress distribution on the insulator. To find out a single design parameter having the highest impact on electrical stress distribution, DFFITS and DFBETAS plots are used. These plots signify that input parameter $\mathrm{X}_{4}$ or insulator outer edge radius $\left(r_{o s}\right)$ are the most influential parameters in insulator sizing. Maximum stress occurs on the insulator outer edge radius and chances of insulation breakdown is high in this area. To improve the reliability of the high voltage insulator, the outer edge radius must be designed carefully, so that it can withstand the high electrical stress occurring on it. 


\section{CONCLUSIONS}

A $220 \mathrm{kV}$ suspension type long rod silicon based insulator having 71 sheds is designed. To reduce the electrical stress on the insulator, design optimization is done and the effect on the electrical stress is studied. The design parameters includes flange angle, flange radius, core radius, insulator outer edge radius, and electrode radius. One parameter is changed at a time while keeping others constant and the electrical stress is calculated. The design, which gives the minimum electrical stress, is taken and, then, the other parameters are varied. In this way, for each parameter the design, which gives the minimum stress, is taken and, finally, the optimized design is obtained. Further it was required to determine the dependence of the output on the input design parameters, so that it helps in finding the fragile design parameter. It is observed that the parameter insulator outer edge radius is the most influential in affecting the electrical stress on the insulator. The design, presented in this paper, helps in reducing the electrical stress by $13.2 \%$ and determining the most influential design parameter. This will facilitate better health monitoring, improved life, and reliability of the insulator.

\section{REFERENCES}

[1] M. Talaat, A. El-Zein, and M. Amin, "Electric field simulation for uniform and FGM cone type spacer with adhering spherical conducting particle in GIS", IEEE Transactions on Dielectrics and Electrical Insulation, vol. 25, no. 1, pp. 339-351, 2018. DOI 10.1109/TDEI.2018.006980.

[2] Y. Lv, J. Li, X. Zhang, G. Pang, and Q. Liu, "Simulation study on pollution accumulation characteristics of XP13-160 porcelain suspension disc insulators", IEEE Transactions on Dielectrics and Electrical Insulation, vol. 23, no. 4, pp. 2196-2206, 2016. DOI: 10.1109/TDEI.2016.7556495.

[3] M. Costabel, and F. J. Sayas, "Time-dependent problems with the boundary integral equation method", in Encyclopedia of Computational Mechanics Second Edition, pp. 1-24, 2017. DOI: 10.1002/9781119176817.ecm2022.

[4] J. Jiao, L. Li, B. Wu, and C. He, "Novel capacitive proximity sensors for assessing the aging of composite insulators", Sensors and Actuators A: Physical, vol. 253, pp. 75-84, 2017. DOI: 10.1016/j.sna.2016.11.025.

[5] S. M. Ale-Emran and M. Farzaneh. "Parametric studies and improved hypothesis of booster-shed effects on post insulators under heavy icing conditions", IEEE Transactions on Dielectrics and Electrical Insulation, vol. 22, no. 1, pp. 420-427, 2015. DOI: 10.1109/TDEI.2014.004619.

[6] M. Bouhaouche, A. Mekhaldi, and M. Teguar, "Improvement of electric field distribution by integrating composite insulators in a $400 \mathrm{kV}$ AC double circuit line in Algeria", IEEE Transactions on Dielectrics and Electrical Insulation, vol. 24, no. 6, pp. 3549-3558, 2017. DOI: 10.1109/TDEI.2017.006011.

[7] S. A. Bessedik, R. Djekidel, and A. Ameur, "Performance of different kernel functions for LS-SVM-GWO to estimate flashover voltage of polluted insulators", IET Science, Measurement \& Technology, vol. 12, no. 6, pp. 739-745, 2018. DOI: 10.1049/iet-smt.2017.0486.

[8] S. Zhao, X. Jiang, and Y. Xie, "Evaluating the contamination level of polluted insulators based on the characteristics of leakage current", International Transactions on Electrical Energy Systems, vol. 25, no. 10, pp. 2109-2123, 2015. DOI: 10.1002/etep.1951

[9] K. H. Lee, S. G. Hong, M. K. Baek, H. S. Choi, Y. S. Kim, and I. H. Park, "Alleviation of Electric Field Intensity in High-Voltage System by Topology and Shape Optimization of Dielectric Material Using Continuum Design Sensitivity and Level Set Method", IEEE Transactions on Magnetics, vol. 51, no. 3, pp. 1-4, 2015. DOI: 10.1109/TMAG.2014.2358845.

[10] J. A. Virbalis, R. Lukocius, P. Marciulionis, G. Nedzinskaite, and P Vaskys, "Investigation of the electric field of metallic fence under a high voltage transmission line", Elektronika ir Elektrotechnika, vol. 22, no. 6, pp. 22-27, 2016. DOI: 10.5755/j01.eie.22.6.17218.

[11] J. Wang, B. Vue, X. Deng, T. Liu, and Z. Peng, "Electric field evaluation and optimization of shielding electrodes for high voltage apparatus in $\pm 1100 \mathrm{kV}$ indoor DC yard", IEEE Transactions on Dielectrics and Electrical Insulation, vol. 25, no. 1, pp. 321-329, 2018. DOI: 10.1109/TDEI.2018.006890.

[12] D. Rabah, C. Abdelghani, and H. Abdelchafik, "Efficiency of some optimisation approaches with the charge simulation method for calculating the electric field under extra high voltage power lines", IET Generation, Transmission \& Distribution, vol. 11, no. 17, pp. 4167-4174, 2017. DOI: 10.1049/iet-gtd.2016.1297.

[13] M. Sarajlic, P. Kitak, and P. Pihler, "New design of a medium voltage indoor post insulator", IEEE Transactions on Dielectrics and Electrical Insulation, vol. 24, no. 2, pp. 1162-1168, 2017. DOI: 10.1109/TDEI.2017.005947.

[14] R. Stanforth, E. Kolossov, and B. Mirkin, "Hybrid k-Means: Combining Regression-Wise and Centroid-Based Criteria for QSAR" in Selected Contributions in Data Analysis and Classification, Berlin Heidelberg: Data Analysis, and Knowledge Organization. Springer, pp. 225-233, 2007. DOI: 10.1007/978-3-540-73560-1_21.

[15] M. Costabel, "Principles of Boundary Element Methods", Computer Physics Reports, vol. 6, pp. 243-274, 1987. DOI: 10.1016/01677977(87)90014-1.

[16] T. H. Fawzi and Y. Safar, "Boundary methods for the analysis and design of high voltage insulators", Computer Methods in Applied Mechanics and Engineering, vol. 60, pp. 343-369, 1987. DOI: 10.1016/0045-7825(87)90139-3.

[17] P.B. Zhou, Numerical Analysis of Electromagnetic Fields. Germany, Berlin: Springer-Verlag, 1993. DOI: 10.1007/978-3-642-50319-1.

[18] M. D. Cattaneo, M. Jansson, and W. K. Newey, "Inference in linear regression models with many covariates and heteroscedasticity", Journal of the American Statistical Association, vol. 113, no. 523, pp. 1350-1361, 2018. DOI:10.1080/01621459.2017.1328360.

[19] D. Cheng, Y. Shi, T. Lin, B. H. Gwee, and K. A. Toh, "Hybrid K Means Clustering and Support Vector Machine Method for via and Metal Line Detections in Delayered IC Images", IEEE Transactions on Circuits and Systems II: Express Briefs, vol. 65, no. 12, pp. 1849 1853, 2018. DOI: 10.1109/TCSII.2018.2827044.

[20] H. Harb, A. Makhoul, and R. Couturier, "An Enhanced K-Means and ANOVA-Based Clustering Approach for Similarity Aggregation in Underwater Wireless Sensor Networks", IEEE Sensors Journal, vol. 15 , no. $10, \quad$ pp. 5483-5493, 2015. DOI 10.1109/JSEN.2015.2443380.

[21] D. Derryberry, K. Aho, J. Edwards, and T. Peterson, "Model selection and regression t-statistics", The American Statistician, vol. 72, no. 4, pp. 379-381, 2018. DOI: 10.1080/00031305.2018.1459316.

[22] J. Koskinen, P. Wang, G. Robins, and P. Pattison, "Outliers and Influential Observations in Exponential Random Graph Models", Psychometrika, vol. 83, no. 4, pp. 809-830, 2018. DOI: 10.1007/s11336-018-9635-8.

[23] T. S. Açar, and M. R. Özkale, "Influence measures based on confidence ellipsoids in general linear regression model with correlated regressors", Journal of Applied Statistics, vol. 43, no. 15, pp. 2791-2812, 2016. DOI: 10.1080/02664763.2016.1144726. 